This is the accepted version of the following article:

\title{
EVOLUTION OF RELIGIOUS CAPACITY IN THE GENUS HOMO: ORIGINS AND BUILDING BLOCKS
}

by Margaret Boone Rappaport, Christopher J. Corbally,

in Zygon: Journal of Religion and Science, vol. 53, no. 1 (March 2018), pp.123-158,

which has been published in final form at

https://authorservices.wiley.com/api/pdf/fullArticle/14854784.

This article may be used for non-commercial purposes in accordance with the Wiley SelfArchiving Policy [https://authorservices.wiley.com/author-resources/Journal-Authors/licensingopen-access/open-access/self-archiving.html]

\begin{abstract}
.
The large, ancient ape population of the Miocene reached across Eurasia and down into Africa. From this genetically diverse group, the chimpanzees, bonobos, gorillas, and humans evolved from populations of successively reduced size. Using the findings of genomics, population genetics, cognitive science, neuroscience, and archaeology, the authors construct a theoretical framework of evolutionary innovations without which religious capacity could not have emerged as it did. They begin with primate sociality and strength from a basic ape model, and then explore how the human line came to be the most adaptive and flexible of all, while coming from populations with reduced genetic variability. Their analysis then delves into the importance of neurological plasticity and a lengthening developmental trajectory, and points to their following article and the last building block: the expansion of the parietal areas, which allowed visuospatial reckoning, and imagined spaces and beings essential to human theologies. Approximate times for the major cognitive building blocks of religious capacity are given.
\end{abstract}

Keywords:

ape; bottleneck; cognitive evolution; effective population size; founder effect; genetic drift; natural selection; plasticity; population genetics; sociality.

Margaret Boone Rappaport is an anthropologist, biologist, and co-founder of the Human Sentience Project, Tucson, AZ, USA; e-mail: msbrappaport@aol.com.

Christopher J. Corbally, SJ, is an astronomer with the Vatican Observatory and Department of Astronomy, University of Arizona, Tucson, AZ, USA and co-founder of the Human Sentience Project; e-mail: corbally@as.arizona.edu. 


\section{EVOLUTION OF RELIGIOUS CAPACITY IN THE GENUS HOMO: ORIGINS AND BUILDING BLOCKS}

Margaret Boone Rappaport, Christopher J. Corbally

The world can sometimes seem a violent place, but we are steadily becoming a more democratic and peaceful species, more cooperative, kinder, more empathetic, and more generous, descended from more aggressive ancestors in our not-too-distant past. We are still being tamed by culture, and if there are genetic differences among us that map onto these more peaceable natures, they will be finding favor in our ranks.

Mark Pagel, Wired for Culture (2012, 266)

\section{INTRODUCTION}

This is the first in a series of three papers whose purpose is to describe the theoretical underpinnings for an evolutionary model of the biological emergence of religious capacity in the genus Homo (Table 1). Because religious capacity is essentially a cognitive trait, and the timing of human cognition has become an issue (MacLean 2016), our emphasis is on the timing of adaptations at the root of human religious capacity. In this first paper in a series of three (Rappaport and Corbally 2018a), important building blocks are identified, probed, and set in place for a model that is presented more fully in the next paper, "Evolution of Religious Capacity in the Genus Homo: Cognitive Time Sequence" (Rappaport and Corbally 2018b). The latter explores additional genomic, neurological, and cognitive findings that support construction of our model for religious capacity's biological evolution. A third paper in the series, "Evolution of Religious Capacity in the Genus Homo: Trait Complexity in Action through Compassion” (Rappaport and Corbally 2018c) includes an analysis of the very complex human capacity for compassion using the stages in our evolutionary model; application of neural reuse theory and interpretation of it in a Darwinian context; and finally, a teaching tool on religious capacity in early Homo sapiens. The action in the latter frames the phenotypic expression of the human trait of religious capacity and the human ability to form compassion, both now and in the past. We use the term "trait" in the sense used by biologists (Varki and Altheide 2005, their Table 1).

We hasten to add that our term "building block" implies a collection of traits or characteristics that appear together and are generally discrete both through time and sometimes among related species. The "building block" implies discreteness, strength, and adaptive advantage, and they are useful in demonstrating a solid biological foundation for religious capacity. We use "building block" to imply an adaptation or a set of related adaptations that are reliably reproduced in a species or a series of species. 
Table 1. Classification of the Order Primates, Commonly Known Forms

\begin{tabular}{|c|c|}
\hline Kingdom & Animalia \\
\hline Phylum & Chordata \\
\hline Class & Mammalia \\
\hline Order & Primates \\
\hline \multirow{4}{*}{$\begin{array}{l}\text { "lower primates" } \\
\text { "monkeys" }\end{array}$} & Lemurs and lorises \\
\hline & Tarsiers \\
\hline & New World monkeys \\
\hline & Old World monkeys \\
\hline Superfamily & Hominoidea (lesser apes, great apes, humans) \\
\hline Family & Hylobatidae: gibbons (lesser apes) \\
\hline Family & Hominidae (great apes and humans) \\
\hline Subfamily & Ponginae (orangutans) \\
\hline Subfamily & Homininae (gorillas, chimpanzees, humans) \\
\hline Tribe & Gorillini (gorillas) \\
\hline Tribe & Hominini: (chimpanzees and humans) \\
\hline Genus & Pan (chimpanzees and bonobos) \\
\hline Species & Pan troglodydtes (chimpanzee) \\
\hline Species & Pan paniscus (bonobo) \\
\hline Genus & Homo (humans and extinct related forms) \\
\hline Species & Homo habilis (extinct) \\
\hline Species & Homo erectus (extinct) \\
\hline Species & Homo heidelbergensis (extinct) \\
\hline Species & Homo neanderthalensis (extinct) \\
\hline Species & Homo sapiens \\
\hline Subspecies & Homo sapiens idaltu (extinct) \\
\hline Subspecies & Homo sapiens sapiens \\
\hline
\end{tabular}

We hasten to add that our term "building block" implies a collection of traits or characteristics that appear together and are generally discrete both through time and sometimes among related species. The "building block" implies discreteness, strength, and adaptive advantage, and they are useful in demonstrating a solid biological foundation for religious capacity. We use "building block" to imply an adaptation or a set of related adaptations that are reliably reproduced in a species or a series of species.

There is a naturally fuzzy quality to these building blocks because traits that are eventually called "human" may have very ancient genetic roots in our pre-sapiens ancestors. The building blocks appear variable because of the statistical methods used in population genetics, which is based on probability theory. We further explore this quality in fascinating detailed examples, below, and reveal that some members of Homo sapiens have gene copies that go back as much as two million years, maybe more. In a general way, we all have features that derive from the first primates, then the first apes, and then our closer ancestors, the earlier members of the genus Homo. 
The human trait of religious capacity has very ancient roots - not religious behavior per se, but the roots of it. The "building block" is an analytic artifice that helps us image the most important evolutionary changes that led to a species with religious capacity, whether it finds overt expression in individuals or not. There is substantial overlap in these "building blocks," which represent types of changes through time, although we consider them in their order of first appearance according to our model. It is especially important to note that religious capacity need not be expressed to be present and available in the biology of the population that constitutes our species today. Similarly, no human must learn to read in order for the cognitive capacity that allows us to learn to read to be a trait of our species ( $c f$ Colagè 2015; Rappaport and Corbally 2016).

Our goal here is not to search for signs of "religion" in the fossil record of apes or in the archaeological record of early hominins, or, in the results of modern genomics. We are leery of simplistic answers to questions about religious capacity, and find claims of "God genes" and the like to be facile explanations that ignore how exceptionally elaborate human religious capacity is and how many brain capacities it may draw upon. We propose that the complexity of religious capacity has roots. When one adds evolutionary depth to the exploration of religious capacity's underpinnings, the image that emerges is one of a rich texture of stepwise genetic changes through millions of years of adaptation to changing environments. Was there a single quantum jump that produced religion? Most assuredly, there was not. Were there adaptations without which religious capacity today would not exist, or would be very different? Most assuredly, there were.

The Miocene ape radiation (Table 2) provided the genetic variability and the basic ape model that is historically ours. We share it with other species, but the distinctiveness that emerged in the human species is ours alone. Through the evolutionary process, we emerged with a new terrestrial way of life, new body proportions, then morality, and finally, we evidenced religious thinking. This emergence occurred by chance until very late in human evolution, when cognitive feedback loops developed to facilitate the fixation of some advantageous cognitive adaptations. We explore these loops several times in these papers, and have previously done so for the emergence of morality in Homo erectus (Rappaport and Corbally 2016).

We emphasize that ours is not a capricious sequence of development, for example, our placing moral capacity's evolutionary development earlier than religious capacity's. Our model relies on solid fossil, demographic, cognitive, neurological, and developmental findings. Philosophers and psychologists may have suggested other sequences, but we have not seen their proofs using a full range of new scientific findings from neuroscience, cognitive science, and genomic science, which might argue for a different sequence. We invite others to review these literatures and suggest different models. Ours surely will not be the last. 
Table 2. Geological and Biological Time Periods

\begin{tabular}{|c|c|c|c|}
\hline Era & Epoch & Life & Time \\
\hline \multirow{7}{*}{ Cenozoic } & Holocene & \multirow{7}{*}{$\begin{array}{l}\text { Extinction of } \\
\text { Dinosaurs }\end{array}$} & $\begin{array}{l}11,700 \text { years - } \\
\text { present }\end{array}$ \\
\hline & Pleistocene & & $\begin{array}{l}2.588 \text { mya }-11,700 \\
\text { yrs. }\end{array}$ \\
\hline & Pliocene & & $5.332-2.588$ mуа \\
\hline & Miocene & & $23.03-5.332 \mathrm{mya}$ \\
\hline & Oligocene & & $33.9-23.03$ mya \\
\hline & Eocene & & 55.8 - 33.9 mya \\
\hline & Paleocene & & $65.5-55.8$ mya \\
\hline \multirow{3}{*}{ Mesozoic } & Cretaceous & \multirow{3}{*}{ "Age of Reptiles" } & $145.5-65.5$ mya \\
\hline & Jurassic & & $199.6-145.5$ mya \\
\hline & Triassic & & $251.0-199.6$ mya \\
\hline Paleozoic & & $\begin{array}{l}\text { "Age of Amphibians" } \\
\text { "Age of Fishes" } \\
\text { "Age of } \\
\text { Invertebrates" }\end{array}$ & 542.0 - 251.0 mya \\
\hline Proterozoic & & \multirow{3}{*}{$\begin{array}{l}\text { Multicelled } \\
\text { organisms } \\
\text { One-celled organisms } \\
\text { Origin of Earth }\end{array}$} & $2500-542.0$ mya \\
\hline Archean & & & $4000-2500$ mya \\
\hline Hadean & & & 4600 - 4000 mya \\
\hline
\end{tabular}

Data source: University of California Museum of Paleontology (online). Key: mya = millions of years ago

Again, because the sequence of human cognitive evolution has emerged as a major issue, it is a central topic of the second paper. We build toward that in the first paper, and make good use of earlier papers in Zygon (Rappaport and Corbally 2015; 2016; 2017). Together, they place a rudimentary moral capacity at around 1-1.5 million years ago with Homo erectus. The time frame has stretched backward (and may stretch further) because of important finds at Wonderwerk Cave in South Africa, showing control of fire and cooking at one million years, probably by Homo erectus (Berna et al. 2012). If these finds hold, then Homo erectus and the context we call "The Human Hearth" may have arisen even earlier than we initially proposed (one million years).

Moral capacity, when examined by itself without a religious context, is essentially a cognitive decision-making capacity that makes evaluations along a timeline, with a valence of good to bad for members of the genus Homo. It remains far simpler than religious capacity, we believe, although almost all aspects of early moral capacity are eventually incorporated into religious behavior by Homo sapiens. There are some human institutions that apply moral evaluation outside a religious context, but not many, including some voluntary associations. We suggest that a good measure of "complexity" might be the number of brain capacities each of these adaptive capacities draws upon. Indeed, neuroscientist Michael Gazzaniga writes that, "our big human brains have hundreds if not thousands more individual capacities. ... what is amazing about the human brain is the sheer number of capacities" (Dana Foundation 1999). 
Our view is that religious capacity is vastly more complex than moral capacity if seen by itself, which it rarely is, in human life now. Our contentions about the sequence of moral and religious capacities' emergence will be addressed again and again from various viewpoints in the three papers because the timing of major events in our cognitive evolution are still being clarified (MacLean 2016).

It is important to mention a further aspect of the "building block" construct we use. While it implies discreteness, its temporal borders are not hard and fast. We describe a basic sequence that places moral capacity emerging before religious capacity, but that is not to say that some aspects of human behavior that were eventually incorporated into religion did not exist before the first full flowering of religious capacity (religious thinking) in Homo sapiens. For example, we address the possibility that ritual, drama, and storytelling were part of the learning context called, "The Human Hearth," for Homo erectus. Yet, while ritual is important, it is not religion, by itself.

In a parallel way, we propose that the down-regulation of aggression, which is so important in religious capacity's emergence, occurred initially in the precursor population of ancient apes giving rise to the chimpanzees and humans. MacLean (2016) also proposes an additional bout of the down-regulation of aggression after the species Homo sapiens emerged. The principal evolutionary changes that allowed religious capacity to emerge took place in both major and minor episodes, in fits and starts, over many millennia.

As our model emerged from a cross-referencing of findings from paleoneurology, neuroscience, paleoanthropology, ethnography, and cognitive science, we began to pin the full flowering of religious capacity to the ability to construct well integrated theories about the relationships between humans and the supernatural. That seemed to cover all known human religions. These "theories" or "theologies" - various systems in various cultures - all relied on an evolutionary development for which there is no evidence before Homo sapiens evolved 200,000 to 400,000 years ago (Hublin et al. 2017), and which enables theological thinking. The development of religious capacity is reflected physically in the geometric manner of the final expansion of human parietal lobes, especially the precuneus (Bruner and Iriki 2016; Bruner et al. 2017), and the emergence of a fully globular skull, clearly marked in the fossil record of our species, Homo sapiens. Recent finds at Jebel Irhoud, Morocco suggest that the emergence of the shape of the human skull occurred perhaps more gradually than heretofore thought (Hublin et al. 2017).

It is important to note here that until very recently, the 200,000-year horizon for a relatively rapid emergence of a globular skull had been relatively firm, only to fall away to new finds from Jebel Irhoud, near Marrakesh in North Africa. The anthropologists publishing these finds at around 300,000 years ago emphasize the "pan-African" origin of Homo sapiens, i.e., from East Africa, South Africa, and now North Africa, and a period of development that was perhaps more gradual from 400,000 years ago (Hublin et al. 2017). The modern globular skull shape may have evolved more slowly as a result of a gradual expansion of the parietals. The implication for our model is that, if so, then the capacities to develop theologies also may have developed more gradually, rather than a sudden manner. This does appear logical to us. A more gradual emergence of a fully globular skull is more consistent with our knowledge of the conservative nature of genetic 
changes. Only very rarely do traits appear suddenly. More often, it is an accretion of changes until an adaptation is fixed solidly, and that fixation involves cognitive feedback loops toward the latter stages of human emergence, where we helped to fix traits that were advantageous.

When analyzed by itself, we suggest that the complexity of moral capacity in Homo erectus does not even begin to match the eventual complexity of religious capacity as it emerges in Homo sapiens, to be a fundamentally pro-social trait that supports the social group. We should point out here, as we do several times in these papers, that we view religious capacity as separable - at least, analytically. While the institutions of religion can go awry, and while they can become hateful in some of their practices, we would argue that religious capacity does not alter, it is simply co-opted for the use of political and economic goals. We do not see the essential prosocial nature of religious capacity, as a biologically based trait, to be the reason for inhumane practices that can be falsely labeled, "religious.” We suggest looking elsewhere.

We want to emphasize - just once in these three papers - that theories of the evolution of religious capacity do not discount any human religious faith. Some individuals might incorrectly describe our theoretical model as "Godless." We see the matter differently. We two authors come from two different sciences (anthropology and astronomy), both of which explore, explain, and even extoll the marvels of natural evolution. Stars evolve. Species evolve. The wonders of the universe are no less and no more inspiring than the wonders of biological evolution. From our viewpoint, science does not erase faith, but indeed can support it if one chooses. One has a choice. One can have both science and religion. We evolved that way.

\section{ANCIENT APES}

The first "building block" for religious capacity was a large and varied population of ancient apes from the ape radiation in the Miocene epoch, which lasted from 23 to 5.3 million years ago. The term "large" can be applied to these ancient, Eurasian and African apes in four ways. In all these senses, the human species finds much of its strength and adaptive nature, as well as additional handy traits we describe in later sections. By "large”, we mean:

(1) Genetic variability. The Miocene apes had good genetic variability and a larger "effective population size" than humans came to have. "Effective population size" is a calculated statistic using the theory of population genetics, and it implies genetic variability - genetic differences a very good thing because the more variability a population has, the more chances there are for advantageous mutations. (Most mutations are bad). Effective population size is not a real number of individuals, but the theoretical number of breeding individuals who contribute to the next generation.

(2) Number of genera (pl. genus).

(3) Census population, or the actual number of individuals, whether they breed or not. The census population is often estimated at three times the effective population size.

(4) Size. Ancient apes were physically large, reproduced and matured slowly, and already had large brains. These features were important for their descendants.

Our original interest in the ancient ape ancestral population was driven by a deceptively straightforward question about primate evolution and religion. We wondered: How did an 
ancestral line that originated in relatives of today's tree shrews at the end of the Mesozoic Era (about 65 million years ago), and that began with prosimians at the beginning of the Cenozoic Era (often called the Age of Mammals), produce a sentient human species almost 65 million years later that is able to plan and act together in groups that total millions, and capable of such extraordinary self-reflection that it elicits exclamations that humans seem "psychologically damaged, in ways that suggest some deep break with nature" (Korsgaard 2009, 104), and, as well, a species that can be - according to self-descriptions - seized with such a sense of longing, fulfillment, and motivation by experience they call "religious", that these experiences can move and organize millions over thousands of years? That is quite a 65-million-year story! We were hoping that advances in neuroscience, genomics, and cognitive science would provide clues about religious capacity's evolutionary history. They have. In the following exploration of ancient apes, we see where much of our own strength and adaptive nature were born.

The ancient ape ancestral population from which all great ape and human species evolved had demographic features affecting all these species' evolution (Harris 2015; Prado-Martinez et al. 2013). An understanding of this large and diverse population of ancient apes can suggest ways in which their genetic constitution may have been involved in the evolution of capacities in later species, including humans (both living and extinct species).

Using the principles of population genetics, experts in genomics can determine how speciation likely occurred, for example, the emergence of the human lineage around 7-8 million years ago from an ancestor population that they shared with modern chimpanzees and bonobos. An even larger ape population that was ancestor to humans and chimpanzees was also ancestor to the more distant gorilla, which split from the human-chimpanzee population around 10 million years ago (Scally et al. 2012, 169). The branching patterns are called "species trees," and they often indicate the relative sizes of ancient populations and general time frames between speciation events.

Calculation of "coalescence times" (when two species shared an identical copy of a single gene) allows the construction of a different type of diagram - "gene trees." Humans have many genes (around 21,000) so the calculation of coalescence times for many genes and construction of their gene trees may give conflicting results for how species diverged. Therefore, results are often stated in terms of probability. This variable quality of speciation from the calculation of many coalescence times (for the many shared gene homologues), and their resulting gene trees, give the nature of our understanding a "fuzzy" quality. In fact, some genes once shared by humans and chimpanzees have coalescence times more than a million years ago, long before Homo sapiens emerged. That antiquity imparts an even deeper and more nebulous quality to our image of the ancient ape genetic profile, much of which is recorded in the genomes of great apes and humans. Modern genomes are a type of historical record.

Eugene Harris underscores the major reason that an understanding our ancient ape ancestral population is so important: While we are a young species, even with the latest finds from Jebel Irhoud taking Homo sapiens back to 300-400,000 years ago, we have very ancient roots:

Remember that for about one-third of our genome, we are not most closely related to chimpanzees (and bonobos). This part of our genome is very ancient and 
emerged even prior to the time when gorillas split from chimpanzees and humans (Harris 2015, 56-57).

The very ancient copies of genes that some humans now carry with them are interesting with respect to our evolutionary history. For example, Eugene Harris and Jody Hey sequenced a portion of the gene PDHA1, which is a protein-coding gene on the X chromosome, for an enzyme used in energy metabolism (Harris 2015, 63; Harris and Hey 1999). They found that differences in this gene among living people went back to very ancient times, well before 200400,000 years ago, when the species Homo sapiens emerged. In fact, these scientists traced gene copies to around two million years ago, when Homo habilis was still alive! This species of the genus Homo remains the earliest known fossil in our genus. Harris and Hey’s work with very ancient gene copies is not the only research showing "deep divergences" in human gene trees. For example, Blum and Jakobsson (2011) give results from a broad survey of 60 nuclear segments that include very old, living genes going back 1 to 1.5 million years ago - the time of Homo erectus.

The genes that facilitate energy metabolism are important in the evolution of the human lineage because of fundamental changes in foraging and food-getting strategies, from the ancestral great ape to the modern human. Harris points to the work of Morris Goodman and colleagues in noting that, "a relatively large fraction of genes involved in aerobic cellular respiration ... have undergone repeated bouts of adaptation in human evolutionary history. These genes show repeated functional changes over evolutionary time in the protein-coding sequences..." (2015, 94; Grossman et al. 2004). Even more recently, Perdomo-Sabogal and colleagues (2016) reported a global gene regulator or "master genetic switch" (Caspermeyer 2016) - GABPa - that affects cell energy, growth, and demise, especially at sites in the brain, nervous system, and spinal cord. GABPa is found on one of the Human Accelerated Regions of the human genome (Pollard 2009), and it likely arose in our evolution to help supply an enlarging brain with energy.

Because of the evolutionary importance of metabolic processes geared to feeding a larger brain in the genus Homo, metabolism in the modern human has become a focus of research. Kuzawa reports that, "the brain's metabolic requirements peak in childhood, when it uses glucose at a rate equivalent to $66 \%$ of the body's resting metabolism and $43 \%$ of the body's daily energy requirement... Our findings support the hypothesis that the unusually high costs of human brain development require a compensatory slowing of childhood body growth" (2014, 13010). In other words, the energy drain on the evolving species of the genus Homo was so significant that the trajectory of development changed. Of course, changes in many systems were involved in the lengthening of childhood in human evolution, including relatively late cognitive maturation ( $c f$ Thompson-Schill, Ramscar, and Chrysikou 2009; Rappaport and Corbally 2016, 861). In this exploration of the evolutionary building blocks leading toward religious capacity in the genus Homo we will refer repeatedly to the many and important consequences of this change in developmental pace.

It is important to remember that by the time we see the small bipedal ape, Homo habilis, in the fossil record, the brain was already relatively large and presenting this early member of our genus with the problem of obtaining enough energy to supply its requirements. Given that Homo habilis was making a transition in niche from the ape pattern of foraging and sleeping in trees, to 
the more human pattern of aggressive scavenging of meat during the day (Coolidge and Wynn 2009, 207), it is not surprising that energy metabolism was changing. Homo habilis needed meat to feed its already-enlarging brain, an energy-hungry organ.

Apes existing today are sometimes called "relics" of the Miocene ape radiation that produced a large, varied population (in terms of both census population and effective population size), from which later human and anthropoid ape species diverged (Casanovas-Vilar 2011). Both Old World monkeys and great apes had first appeared in Africa. The best known of these apes was Proconsul, who arose 23-25 million years ago, and had both monkey and ape features. Then, by the middle of the Miocene, around 14-16 million years ago, a land bridge to Eurasia opened up because sea levels dropped, and apes colonized Eurasia, along with many other fauna. They produced a diverse ancient population of at least 14 genera (Begun 2003, 76). Most ancient apes became extinct, but one led to later species of African great apes and humans. Begun diagrams this Last Common Ancestor (LCA) at about 12 million years ago, although who that LCA was, exactly, is still not clear $(2016,3)$.

\section{COMING FROM A SMALLER FAMILY}

The deep (temporal) divergences of some living gene copies quietly suggest that what we call "human" began its evolution before our species evolved, in fact, millions of years before our species emerged, if we are to take a lesson from results on the PDHA1 gene segment that Harris and Hey sequenced (1999). How our evolution proceeded from the ancient ape ancestral population to the present depended in many ways on population size and genetic diversity. As we noted previously, the extent of genetic variability in a population is often spoken of in terms of "effective population size" $\left[N_{\mathrm{e}}\right]$ - a statistical concept reflecting the size of the breeding population, i.e., those individuals who contribute to the next generation, often about one-third of the "census population."

The greatest change in effective population size during human evolutionary history was a drop from the ancestors of all great apes (throughout all of Eurasia and Africa) to the African great apes only. Then, there were additional drops in effective population size between the African great apes and the precursor population to the chimpanzee and human lineages. "The drastic 5fold decline in population size between the ancestral lineage of the great apes and the ancestral lineage of the Homininae coincides with a possible dispersal event from Eurasia to Africa in the late Micocene” (Schrago 2013, 42).

Schrago diagrams a population drop from 40 million years ago, at around 1,200,000 for the effective population size of Anthropoidea (monkeys, and what would evolve into apes and humans), to an effective population size of the human-chimpanzee (genus Homo-genus Pan) ancestral population at around 6 million years ago, of approximately 30,000. This is a very large drop in effective population size, and a tremendous loss in genetic diversity.

As noted, the biggest drop was from the large Eurasian ape population to an Africa-only population (Schrago 2013, 43, Fig. 4, lower). The latter included what would become the human lineage. One can clearly visualize what this author suggests: “...the occurrence of a genetic bottleneck during the evolution of Homininae [a subfamily of Hominidae], which corroborates 
the origin of African great apes from a Eurasian ancestor” (Schrago 2013, 37 and 43). The reference to "bottleneck" underscores that the genetic variability of the African apes was only a portion of the genetic variability in the original, larger ape population throughout Europe, Asia, and Africa. The Eurasian origin of our particular ancient ape ancestor is no doubt a surprise to many.

The human lineage was not the only line whose genetic diversity was reduced. An analysis by Prado-Martinez and colleagues finds that "Humans, western chimpanzees and eastern gorillas all show a remarkable dearth [scarcity] of genetic diversity when compared to other great apes. It is striking, for example, that the sequencing of 79 great ape genomes identifies more than double the number of SNPs [single nucleotide polymorphisms] obtained from the recent sequencing of more than a thousand diverse humans...” $(2013,474)$. The work of these researchers suggests that the ancestral ape line that survived the Miocene radiation came originally from Eurasia, but it flowered in Africa to produce different groups of gorillas, chimpanzees, bonobos, and finally humans.

Scally et al. $(2012,174)$ summarize the evolution of great apes this way: "Since the Middle Miocene - an epoch of abundance and diversity for apes throughout Eurasia and Africa, the prevailing pattern of ape evolution has been one of fragmentation and extinction” ( $c$ Begun 2016). Compared to the size and genetic variability of the Miocene apes, the human lineage shows such a great loss of diversity that it is sometimes called a "population crash." Harris asks several practical questions: "How might the dramatic crash have impacted the trajectory of human evolution? Has a population reduction taken a toll on the health of humans today? On the flip side, were there any possible benefits we have enjoyed as a result of living in reduced populations? And what will our vastly larger population numbers on this planet hold in store for us in our evolutionary future?” $(2015,61)$. The reader should keep these questions in mind when we delve deeply into the foundations of religious capacity. Out of this extreme drop in population size and genetic diversity, and the consequences, features emerged that set the human lineage apart.

Human Lineage Specific (HLS) genetic changes have been associated with some diseases in modern humans (Lieberman 2013; O’Bleness et al. 2012). However, it is important to keep in mind that the reduction in effective population size and genetic variability may have allowed both advantageous and disadvantageous mutations to survive. Some HLS changes might have been initially disadvantageous, but subsequently proved advantageous, perhaps in a new environment. Furthermore, had the human line not been reduced to a size where the force of random genetic drift became stronger and the force of natural selection became weaker, some of our modern traits might not have persisted, at all.

Schrago critiques methods for estimating ancient, effective population size. He notes, as others have (e.g. Langergraber et al. 2012), the generation times increase "gradually along the lineage that led to humans and chimpanzees... The generation time of the Homo/Pan [human/ chimpanzee] ancestor was 26.3 years. In the ((Homo, Pan), Gorilla) [((human, chimpanzee), gorilla)] ancestral population it was inferred to be 21.2 years, whereas the generation time of the ancestor of the great apes was estimated to be 15.2 years” (Schrago 2013, 38). Generation times get shorter as one goes backward in evolutionary time. Elsewhere Schrago writes, "the effective 
population sizes of the lineages leading to humans and chimpanzees exhibited a general trend of sequential reduction of the effective number of individuals, from approximately 1,200,000 to 30,000...” (2013, 41).

Generation length would have profound effects on the human lineage that eventually emerged, including on moral (Rappaport and Corbally 2016;2017) and religious capacities. Longevity is an unusual biological trait, and a well accepted Human Lineage Specific trait that involves an elongated developmental trajectory, births of individuals in increasingly immature states, and in this way, the emergence of lengthy and strong social and emotional bonds between individuals. Some types of cognitive maturation could not have been accomplished without a lengthened lifetime of experience. For example, human wisdom does not emerge until well into the twenties, if at all.

In a methodological discussion on estimating ancient effective population size, Schrago (2014) cites different effective population sizes of the human-chimpanzee ancestor, at 35,447 to 50,797 by one method, and 33,347 to 52,327 by another. In his analysis, he derives a figure of 12,000 to 20,000. Still another method comes up with 47,000 to 65,000. Of the common ancestral chimpanzee-human population, Harris writes, "Surprisingly, the common ancestral species was found to have a very large effective population size, ranging anywhere from 52,000 to 96,000, a surprising five to ten times the effective population size of modern humans” (2015, 43-44).

While it is clear that the methodologies for estimating ancient effective population sizes are in flux, it is also clear that the human lineage sustained a severe reduction in size, in comparison to the ancient ape ancestral populations from which it emerged. The effective population size of humans has been repeatedly estimated at around 10,000. "Many genetic systems provide reassuringly congruent estimates: all indicate that human genetic variation is relatively low and that the approximate 'effective' size (i.e., the number of breeding adults) of humans is on the order of 10,000...” (Harpending et al. 1998). It should be remembered that the figure 10,000 is a statistic that represents genetic variability, not census population size. Even with a global population now in the billions, humans still have an effective population size of 10,000 (Harris 2015, 39).

In a search for the effects of this smaller number, Harris reviews the literature on "isolates,” such as island populations and small religious groups, in which there can be substantial inbreeding (2015, 64-67). Recessive genes that create disease are seen more frequently. Isolates often provide an example of the "founder effect," where a small group breaks off with less genetic diversity than the population from which it came. If that group remains isolated, inbreeding will sometimes lay bare disadvantageous genes that cause disease. In a process called "random genetic drift," an isolated group has only a portion of the genetic variability of its ancestral population, and it can “drift” toward an entirely different population profile through the accretion of random mutations.

There has been substantial discussion in the literature on the potential effectiveness of genetic drift alone to affect human evolution, and some scholars opt for a combination of genetic drift and natural selection ( $c f$ Hawks 2008; Lieberman 2008 \& 2013; Weaver and Roseman 2008). We shall return to the example used in these three sources - the modern human globe-like cranial 
form, attained through either genetic drift, natural selection, or both - in our second and third papers, which provide additional factors in the emergence of religious capacity on the human line, including expansion of specific parts of the human brain, in what is now recognized as a unique pattern in Homo sapiens (Bruner and Iriki 2016; Bruner et al. 2017).

Population genetics assumes that there is a tendency for genetic drift to produce groups with reduced genetic diversity over time, sometimes quite rapidly and completely independent of natural selection. It is believed that genetic drift can cause reduced population growth rate, increased risk of extinction, reduced ability to respond to environmental change, and decreased disease resistance. The notion of reducing genetic diversity through genetic drift has now been submitted to experimental testing, and the results are interesting in relation to human evolution and the emergence of our unusual cognitive capacities, including religious capacity.

\section{EXTINCTION OR CRASH}

We now ask how the reduction in genetic variation on the human line happened, and what the consequences were. And, is there any way we can use our population history to comprehend our special human traits, including bipedalism, large brains, exquisite hand-eye coordination, tool use, and socio-cognitive features that enable and undergird human social institutions like kinship and legal systems, morality, and religious capacity? Because of the sparseness of the fossil record, it is useful to turn to the experimental laboratory to understand the mechanisms that may have led from a population "crash" to a new species, probably several times along the human line from Homo habilis, to Homo erectus and Homo heidelbergensis, and finally to Homo sapiens - at minimum. The story may become even more complicated when new fossils are unearthed, new relationships emerge from genomic science, and possibly new species and subspecies are identified.

After we comprehend how the reduction in size of the populations leading to modern humans may have happened, and equally important, that it was, and remains, the result of a combination of natural evolutionary processes, we shall return to what changed to endow Homo sapiens with some of our most distinctive cognitive, emotional, and perceptual features - enhanced and complicated by culture - but still, fundamentally, biologically based, in a series of ancient ape and early hominin populations.

Founder effects have been proposed as a strong force in the generation of new species. In such a case, the founder group, because it is smaller than its ancestral population, contains only a portion of that population's genetic variability. We ask: Is a founder effect what happened, perhaps again and again, on the human lineage? No one is sure, but we can look at the effects of population constrictions on other species, and see how their genetic variability changes with size reduction, and then again, the changes that accompany subsequent expansion ("flush") when a population is allowed to expand once more.

Daniel Matute (2013) notes that the concept of founder effects has been largely untested, so he uses Drosophila (the fruit fly) in an experimental approach to test for so-called "bottleneck effects," where a population becomes isolated and reduced, inbreeding increases, and then the population is allowed to grow substantially again. This general profile seems to describe what 
may have happened to the human lineage over millions of years. The line began in a much larger ancient ape population with substantial genetic variability, and then it became reduced in size with much less genetic variability, only to burgeon again, beginning about 50,000 years ago. After the agricultural and industrial revolutions, the worldwide human population began to achieve the kind of numbers it has now, in the billions, but its effective population size is still 10,000. It genetic variability has remained low.

Matute's results are not ambiguous. He concludes that in his experiments, a "founder effect causes a dearth [scarcity] of genetic variability" (2013, 2306), and a "severe and long-lasting reduction in genetic variability” (2013, 2303). Interestingly, his results "demonstrate that similar to morphological and life-history traits, behavioural traits can be affected by inbreeding and genetic drift” (2013, 2299). He asks, “Are inbreeding and genetic drift able to generate reproductive isolation?” This is an important question. For a population to be reproductively isolated from its ancestral population is a critical issue because if this isolation does not occur, speciation does not occur as readily - or, at all. Matute proposes that, "extreme cases of inbreeding might create ripe conditions for genetic drift and induce the evolution of reproductive isolation in founder populations" $(2013,2300)$. Whatever hinders mating behavior, whether a sea, a mountain range, a disease, or changed behavior, it can prevent a founder population from breeding with its ancestral population, and thereby, can set the stage for reproductive isolation and a new species - for speciation.

Extinction is the most common result of Matute's extreme bottleneck experiment. However, in a small number of cases, founder effects led to pre-mating reproductive isolation, which might prevent re-joining the larger population from which the smaller experimental group was drawn. In other words, inbreeding causes increased reproductive isolation in $0.3 \%$ of the treatments (2013, 2304). He reports that after allowing 30 generations to expand in size ("flush"), genetic diversity does not increase significantly over the time period $(2013,2306)$.

Most important: Whatever genetic diversity was lost, was not regained.

Matute further finds that while "founder effects can be a suitable, but rare, mechanism to generate increased reproductive isolation, natural selection might be required to stabilize any increased reproductive isolation generated by inbreeding” $(2013,2307)$. With these results, we see that speciation on the human lineage could well have been an infrequent occurrence, one in which both genetic drift and natural selection were involved. When speciation occurred on the human lineage, it signaled a major change in niche, even a different socio-cognitive niche (Whiten and Erdal 2012). Indeed, a new and different lifeway at speciation events is exactly what paleobiologists have been asserting for some time, based on fossil evidence.

On the basis of both fossil and genetic evidence, a good estimate for the watershed emergence of Homo sapiens is now - with the recent finds at Jebel Irhoud - earlier than the 200,000-year horizon that had held for some time (Hublin et al. 2017). These anthropologists' fossil finds are dated to more than 300,000 years ago, and emergence of our species may have begun as early as 400,000 years ago. 
A mixture of archaic and modern features is still seen by as late as 200,000 years ago. For example, researchers have returned to the Ethiopian site of Omo, whose fossils Richard Leakey unearthed in 1967, and succeeded in dating the fossils with modern methods to around 195,000 years ago (Fleagle et al. 2008). Anatomically, the fossils include both modern and archaic features of Homo sapiens. It has been suggested that a mixture of ancient and modern features is often found in a fossil record when a species is undergoing a major change in adaptive niche. With the new finds from Jebel Irhoud, we see that our species, Homo sapiens, emerged more gradually, and over the entire continent of Africa (Hublin et al. 2017).

\section{FOREVER LOST}

And still, ours is the latest speciation event on the human lineage. Homo floresiensis, Homo neanderthalensis, and subsequently, the Denisovans broke off from ancestral populations earlier. As a species, we are younger - the youngest, to date, although a side branch, Homo naledi, may have emerged around the same time as Homo sapiens. In this section, we will explore further the reduction of our effective population size, and the probability that humans in Africa emerged in much smaller populations with much less genetic diversity than their ape ancestors. In small populations, genetic drift was stronger, and may have allowed both advantageous and slightly deleterious mutations to survive. This tendency has surely had effects on human health today (Harris 2015,40; O’Bleness 2012), but here, we ask whether it also provided a context in which unusual features could evolve that affected the eventual biological emergence and cultural use of moral and religious capacities.

In the following summary, Matute suggests the potential importance of both founder effects and natural selection for colonization of new habitats and subsequent speciation. Those same forces no doubt operated at some junctures along the human line, and as the evolving populations became smaller, genetic drift would become stronger. Matute's insight provides a context for the evolution of a species that was bright, curious, fully bipedal, and mobile - ours:

The fact that reproductive isolation can arise after founder effects also has implications for our understanding of speciation driven by colonization of new habitats. In these situations, there might be a strong selective pressure to adapt to a new environment, and this can lead to reproductive isolation (i.e. reproductive isolation is mediated by adaptive traits to the new environment). The results here shown suggest that founder effects and small population sizes also induce reproductive isolation without the need of invoking adaptation. [Emphasis added.] These two possibilities are not mutually exclusive, and they might even operate at the same time (i.e. natural selection might help to stabilize the frail premating isolation originated by founder effects).

(Matute 2013, 2307).

In light of these comments, we ask the following question: Were the early African populations of Homo sapiens small and isolated?

It is difficult to draw conclusions from so little fossil evidence, but with additional theory from population genetics, we can better hazard a guess. We understand that the human line has always 
had a rather small effective population size with a genetic variability that was and is much reduced from its ancient ape origins. Therefore, we conclude that the early populations of Homo sapiens were not large and had reduced genetic variability. Could species or sub-species of Homo - especially Homo sapiens - have emerged from one or more "bottlenecks" or as examples of "founder effects" and if so, what does this imply for genetic variability and genetic drift in these groups? What does it mean for both advantageous and disadvantageous mutations, whose effects can show up dramatically in small, inbred populations? Finally, from the perspective of social science, what does the failure of natural selection to eradicate either one (because its force is weak in small groups) mean for their culture?

The literature on population bottlenecks along the human line is filled with proofs and counterproofs, claims and counter-claims. The application of population genetics to human genomics is still in flux. However, at the present, it appears quite certain that there was a bottleneck at about 50,000 years ago when humans left Africa (Harris 2015, 123). That makes sense. Living Africans have far higher genetic diversity than humans elsewhere on the globe. Other humans, elsewhere, are descended from the out-of-Africa population, which surely had less genetic variation than the larger, ancestral, African human population from which it came. The claim that "We are all Africans" carries even more weight with the findings of anthropoid genomics and population genetics. Now, "We are all Eurasian" also carries some weight because that was the origin of the ancestral ape that gave rise to all the African great apes and all members of the genus Homo.

Let us return to Blum and Jakobsson's (2011) interpretation of their broadly drawn data set on deep genetic divergences in living African genomes, some as old as 1 to 1.5 million years, in order to clear up one longstanding debate in paleoanthropology. Using population genetics, these authors write that their results are consistent with another ancient bottleneck in the Middle Pleistocene. They also propose that their findings are consistent with an out-of-Africa scenario if the ancestral effective population size was about 14,000 - well within hailing distance of 10,000. This provides additional support for our low level of genetic variability.

The longstanding debate about a single out-of-Africa scenario vs. continual migration and admixture with extant hominins throughout Eurasia has now been settled in favor of a "very slightly mixed" scenario where a single, rather late (50-60,000 years ago) out-of-Africa human stream to the non-African world is most likely, although there was some admixture from other hominin populations already living in Eurasia. Traces of these early hominins show up in small percentages of living humans’ DNA from Neanderthals and Denisovans.

In summary, research results on bottlenecks are consistent with two conclusions: First, that bottlenecks reduce genetic diversity and second, that once genetic variability is lost, it is difficult, if not impossible to re-capture.

Here, we ask purposefully far-reaching questions that emerge from our knowledge of small population size, reduced genetic variability, and probably the increased effects of genetic drift on the human lineage. We ask whether a reduction in effective population size combined with the growing strength of genetic drift had anything to do with the emergence of factors that form a foundation for what eventually evolved as religious capacity in our species. The importance of 
our model's 150,000-year time frame for full, human religious capacity is concomitant with the expansion of a particular part of the brain (the precuneus), which resulted in the typical globular shape of the human skull (Bruner et al. 2017; Bruner and Pearson 2013). We suggest that essential features of religious capacity likely emerged along with the stabilization of the model for that species, in that time frame, and we explore this contention more fully in the second and third papers in this series. The likelihood of this emergence is based on the shape of human fossil skulls and the type of brain growth that has been proved to cause that change ( $c f$ Bruner et al. 2017).

Still, some traits supporting religious capacity must have already existed by the time Homo sapiens began to emerge. We find the notion that earlier members of the genus Homo suddenly developed complex capacities for religious thinking - unlikely, even illogical. Evolution is usually much more conservative than that. There is rarely anything completely new. In fact, our model for a rudimentary morality places its emergence at the time of Homo erectus, after that species learned to control fire and a learning context called the "Human Hearth" developed 1-1.5 million years ago (Rappaport and Corbally 2016; 2017). We see the human capacities for moral and religious thinking as separate, but related in their expression and application in human social life. We propose that moral capacity came before full religious capacity flowered at the time our species model stabilized around 150,000 years ago (Bruner et al. 2017). However, there were hints beforehand, capacities that were indispensable for an unusual former ape that learned to apply moral and religious thinking to themselves, and to others in the band.

\section{MILLION YEAR BONANZA, AND THE TIMING OF HUMAN COGNITIVE EVOLUTION}

Our task is now to identify which supporting traits came when, and why they were important for religious capacity. Firm answers to questions about when various aspects of human cognition emerged are very likely decades away, but there are hints. So, we ask: Which traits were foundational to religious capacity in earlier ape and hominin populations? Which ones emerged in earlier anthropoid apes, which came with the genus Homo, and which came with the emergence and stabilization of our species, Homo sapiens?

We look at the genetic evidence for the underlying traits that we identify. This is still very early in the developing field of human genomics, and while such questions may be somewhat premature, they will help to evaluate the human genome from as broad a perspective as possible. Indeed, there are already a few (and there are sure to be more) human genes identified that impact moral and religious capacities, especially decision-making and language. We add additional genes to this list in the second paper in this series of three.

The emergence of religious capacity in our species required that sequential layers of mutations be bound with an essential primate sociality that began with the earliest primates 55-65 million years ago, and then, with a basic ape model that emerged in the Miocene, 23 - 5.3 million years ago. This evolutionary process was not so much one of rejection of former traits, but adding to them and regulating others. We glimpse in other primates the origins of many essential features that would eventually make humans, human. For example, Begun (2003, 78; 2016) describes an ape as a primate with no tail, which is enormously important because the limbs and torso had to 
provide flexibility and stabilization of movement that a tail formerly helped to do. Those requirements gave the ape very flexible limbs (including, shoulders, feet, and ankles), big chests, and a more upright posture than most other primates. Apes are also big, and the great apes grow, mature, and reproduce more slowly than other primates. The brains of apes are large, and they are more intelligent than other mammals. Begun writes that by the time of the 19-million-yearold Proconsul, the fossil record contains the earliest, unambiguous ape $(2003,78)$.

We see in the descriptions of ancient apes an upright posture that would eventually prove advantageous for humans in protecting themselves from predators, scavenging, and finally, spear-throwing and social hunting. We see the flexibility of body and limbs that would eventually carry human ancestors away from their ancestral home in Africa, to colonize the rest of the globe, and then, to live comfortably on the International Space Station. The ape's upright posture and flexibility of limbs was a good, if partial, basis for the freeing of the hands, and then, use of them for tool construction and manipulation of the environment. In the ape model, we even see the slower developmental trajectory that will be important for nurturing infants on the human line who are born relatively immature and require significant investments in parenting.

Here, and in the following papers, we search for some of religious capacity's foundations - those developments that made religion a discrete adaptation seen regularly (but not uniformly) in modern children at five or six years old - if the proper stimulus is present, and often even if it is not (Van Slyke 2011). Trait types explored include:

(1) the positive natural selection of some, enhanced sensory capabilities on the human line; (2) the down-regulation of aggression, emergence of social tolerance while feeding, and secondary altriciality, or an extension of the developmental trajectory, so cognitive maturity comes relatively late;

(3) the up-regulation of physical and emotional sensitivity, bound later with an ability called "deep social mind" (Whiten and Erdal 2012) or the hominin facility to develop "a theory of mind" for others (Whiten 1999), and thereby, using neurological features like mirror neurons, a capacity that ultimately potentiates the complicated cognitive/action-oriented human capacity for “compassion” and resulting, socially organized beneficence; compassion receives special treatment in the third paper in this series of three;

(4) the partial over-taking of moral capacity by religious capacity; our model interprets moral capacity as evolving after Homo erectus controlled fire at 1 - 1.5 million years ago, and before Homo sapiens emerged; and,

(5) the growth, networking, and intensive use of specific parts of the brain (well demonstrated with brain scans of relative metabolic rates), which enabled imagined spaces and beings, and construction of theologies about relationships between humans and the supernatural, as well as the potential for a sense of "selflessness" - all theoretically but clearly marked in the fossil record by our species' fully globular skull and smaller, down-turned face (klinorhynchy). The latter is the best marker we have for the appearance of Homo sapiens. Papers two and three provide more details on these latter developments.

It is important to note how many biological systems were involved in the evolution of religious capacity. Changes in perceptions, emotions, skull morphology, explanation-making capacity, decision-making abilities, culture, visuospatial integration and reckoning, and artistic 
imagination formed an integrated whole that finds expression in the variety of human religions we see today, and historically. Of tremendous importance was the emergence of secondary altriciality, noted above, a term that comes from the field of biology. "Altriciality" usually refers to "primary altriciality," where mammals are born in an immature state and remain relatively helpless for a short period of time until they stand, begin nursing, and moving about on their own. Humans are said to have "secondary altriciality" (Varki and Altheide 2005), which is our sense in these papers. This means that their period of relative helplessness is extended, and they must be carried and provisioned by others. The consequences were that the human line involves lengthy periods of maturation and significant investment in parenting, for years. As we note repeatedly throughout these papers, human cognitive maturity comes late, but this allows for lengthy periods of learning and practice with advanced cognitive capacities such as morality, theological thinking, artistic and creative thinking, and above all, excellent decision making skills that we view especially in paper three. An "altricial” pattern of development is consistent with longevity, and therefore, with theories of menopause, yet another human trait ( $c f$ Rappaport and Corbally 2016).

We know that the human line started and has persisted with less genetic variability than its ancient ape ancestral populations. Therefore, how do we explain how the human line went on to produce one of the most flexible, adaptable, successful species on Earth with less genetic variability? Were there any evolutionary mechanisms that compensated for its loss? And, if this loss is a "downside," did it also have an "upside”? An overview of human adaptation by Lachance and Tishkoff emphasizes several points that are germane to these questions.

Humans have a relatively low effective population size compared to chimpanzees... From the nearly neutral theory of evolution, we know that... a greater proportion of our genome is likely to have evolved neutrally compared to chimpanzees... a greater number of genes underwent positive selection in the chimpanzee lineage than the human lineage (Bakewell et al. 2007) [Lachance and Tishkoff 2013, 136].

Our view is that genetic drift may have functioned to fix some human traits. They were not necessarily fixed by natural selection, but are part of our genome more because of neutral chance, and drift (the operation of chance over time). Genetic drift had more of an effect on the human lineage than, for example, on the chimpanzee lineage, where natural selection was stronger - both positive selection and negative selection. Chimpanzees have much more genomic material that was positively selected than humans, who have more "neutral" material (Lachance and Tishkoff 2013, 136).

Given these facts, we suggest that there may have been mechanisms in human evolution that made up for the loss of genetic diversity, compared to our ancestral ape populations, and even in comparison to a species with which we shared a common ancestor, the chimpanzee. These same mechanisms could have given rise to some of the foundations of religious capacity, which we suggest flowered relatively late on the human line. Yet, the foundations were present before the trait we call "religious capacity" emerged, and we assume the same is true for cultural capacity, which emerged long before, and which we eventually see weakly in the chimpanzee but strongly in the human. The presence of culture along both lines suggests that the ancestral ape population 
that gave rise to the lines of chimpanzees (Pan troglodytes and the very different Pan paniscus, the bonobo), as well as the human line, already had at least some of the biological fundamentals underpinning a capacity for culture. As seen on the human line, the ability of cultural capacity to penetrate every aspect of social life was beyond anything we see in the genus Pan. Chimpanzees are very social, but culture is used rarely and somewhat randomly.

\section{GENETIC DRIFT, A SOURCE OF VARIABILITY IN SMALL POPULATIONS}

The human lineage has an effective population size of 10,000. Yet, if our lineage lost variability in comparison to its ancient ape population, it also kept a great deal, too, in terms of mechanisms that produced variability without a diverse genetic reservoir. Humans had the benefit of coming from a large and genetically variable population of ancient apes, and we retain much of that advantage. We suspect that the eventual emergence and persistence of the human lineage rested, in large part, upon that unseen edge. Genetic variability is essential to population quality. Through a type of cell division that produces eggs and sperm, sexual reproduction creates new assortments of the genetic material from parents. In the process, new combinations appear and are tested, advantageous genetic material is kept, and deleterious genetic material is either removed, or kept if it is not life-threatening.

Many slightly deleterious genes are kept in small populations. A good way to rid a population of deleterious genes is through natural selection, which is strongest in large populations - like the human population, now. Harris proposes that, as the modern human population grows larger, the species will be able to improve its defenses against pathogens because natural selection will be stronger. He writes, "The effects of massively augmented population sizes could very well lead to an evolutionary tune-up, in which diverse populations become more exquisitely matched to the varied environments in which they live” $(2015,84)$. This is the upside of human population growth. There are, of course, downsides.

Modern humans have approximately 21,000 protein-coding genes, plus extensive quantities of RNA and DNA-based regulators (also called "genes") that guide and change the expression of one-to-many genes. The regulation of gene expression appears to be the origin of many of the phenotypic differences we see in humans and chimpanzees, although their genomes are around 96 percent "the same.” In addition, there are other mechanisms that add variability to the expression of our genome. We shall consider two very different ones: genetic drift and human plasticity - the first operating at a population level, and the second, at the level of the individual. Both genetic drift and human plasticity could well have contributed to the foundations of cultural, moral, and religious capacities - those essentially human traits that are listed in their order of emergence, according to our model. Does this mean one emerged, stopped, and then the next emerged, and the next? No, there was substantial overlap through time and in interaction amongst these three human capacities.

Let us state an important generalization about the relationship between genetic drift and natural selection. In large populations, natural selection operates more strongly than genetic drift to omit bad mutations (most of the total), and to keep the few good ones ( $c f$ Harris 2015, 67-70). In small populations, genetic drift is stronger because there is less genetic variation and mutations (both good and bad) tend to persist and sometimes become widespread because of inbreeding. It has 
been surprising to us that genetic drift is not routinely considered in the evolution of human cognition (e.g., MacLean 2016, an excellent, very useful summary) or great ape behavior (e.g. Hare, Wobber, and Wrangham 2012, a fascinating analysis of bonobo vs. chimpanzee behavior that we rely upon in our discussion of anthropoid aggression). These sources and many others, too, provide no mention of the potential importance of genetic drift in the evolution and spread of human cognitive capacities, and this may be due to the lack of testing of the concept, Matute (2013) being the exception.

Natural selection seems intuitively more satisfying than genetic drift: If a mutation is "bad," it is "selected" for the dust heap of evolution ("negative selection"). If a mutation is "good," it is "selected" because its bearers are more fit, so they reproduce and pass it on to their progeny ("positive selection"). Natural selection shows up in a genome by a signature "selective sweep" that can be identified visually, upon sequencing the genome (Harris 2015, 138-40). Genetic drift takes more thought. In small populations with relatively little genetic variability, inbreeding causes mutations to persist - both good and bad. Genetic drift begins with a random draw from an ancestral population, and as the founder population becomes isolated, random mutations are added which cause the population profile to drift - to change. As we see in Matute's results, a population characterized by inbreeding and genetic drift might become reproductively isolated but, it might also "need" natural selection to fix a mutation in the population. Natural selection does not cease to operate in small populations; it is simply not as strong.

A further problem in acknowledging the potential force of genetic drift in human populations is the difficulty of finding good examples of both advantageous and disadvantageous genes being fixed in this way. "Isolates" more often provide examples of deleterious genes causing disease and disability due to inbreeding. One of the best examples we have found of the historical fixation of both good and bad mutations is found in Chapter 7 of Cochran and Harpending (2010), who present an extended case study of "Medieval Evolution: How the Ashkenazi Jews Got Their Smarts." In an analysis of bottleneck effects vs. natural selection, they examine an endogamous (in-marrying) European population of the Middle Ages and find both negative and positive effects of isolation and inbreeding, for example: Tay-Sachs disease and two forms of hereditary breast cancer, among other diseases, and an average IQ of 112-115 - the highest mean IQ of any ethnic group known. In this isolated population, genetic drift gave rise to a unique profile of characteristics that persisted until modern times, although exogamy (out-marrying) is now rapidly diluting its consistency today, and has been for some time.

Could this be what happened to early populations of the genus Homo? It seems possible, even likely, that a fully upright and mobile species, always scouting for new sources of food, might have isolated itself repeatedly in new territories, and therefore gone through founder's effect, isolation, and inbreeding where both advantageous and deleterious genes were allowed to persist. Scavenging and gathering bands of Homo erectus were thought to be 100-110 individuals. Hunting and gathering bands of Homo heidelbergensis were 120-130, and Homo sapiens, 150 (Aiello and Dunbar 1993, 188). Early species of the genus Homo would not have had the means to sustain larger groups. Only with Homo sapiens did humans obtain better supplies of food from agriculture, beginning around 10-12,000 years ago - very recently. There could well have been relationships between bands of early species of Homo, as we see among modern hunters and gatherers (who self-identify sometimes with larger units, tribes), but still, these sizes do not 
represent large amounts of genetic diversity. If a group became isolated over a substantial time period, genetic drift could have fixed disadvantageous and advantageous traits, both.

In small groups of early hominins, disadvantageous characteristics such as deformities and disabilities could well have emerged. There is an example of an especially isolated South American native population in whom foot deformities emerged and became widespread in the group, in historical times (Lévi-Strauss 1973 [1955]). Some theories of human origins suggest that individuals with disabilities, like this, placed a premium on other individuals with greater sensitivity, less aggression, and greater compassion (Winder and Winder 2015). Thus, the scenario forms a rationale for the evolution of these human characteristics. It is postulated that, once the advantageous characteristics arose, the issue then becomes how they became widespread, and to answer that, theories of reticulate evolution or "introgressive hybridization" and lateral gene transfer have emerged (Arnold 2008). These scholars challenge the modern synthesis of evolutionary biology that assumes a hierarchy of continuously diverging lineages that never meet again. Instead, they propose that lines of early humans re-converged and hybridized. Isabelle Winder describes the ensuing process this way: “...we believe that anthropologists need an 'Extended Synthesis' able to accommodate situations where lineages reconverge, disabling genes may be flushed out of hiding and organisms are capable of social learning that they then turn to their advantage” (Garner 2015).

There are both practical and theoretical problems with these hypotheses, although the mechanism of reticulate evolution may have operated in some small groups of early hominins. It is possible. However, there appears to be little evidence for early hominins with disabilities, or even theory leading to such a conclusion. It seems unlikely to us that individuals with severe disabilities could have survived the lifeway of early members of our genus - Homo habilis or even Homo erectus. More importantly, we suggest that a down-regulation of aggression, emergence of secondary altriciality, and early types of social beneficence (which seem to be the focus of theories on disabilities) must have occurred substantially earlier than these hypotheses imply, and were widespread earlier. Individuals with disabilities would not have been required for social tolerance to operate effectively, because altriciality and the down-regulation of aggression are part of a well-known complex of biological traits in a variety of species (Hare, Wobber, and Wrangham 2012). Our model suggests that this trait complex had probably emerged in the population of apes just ancestral to bonobos, chimpanzees, and humans, because it appears to have sorted independently into two of them (bonobos and humans). We suggest a different biology took precedence in producing culturally-based beneficence. Our view is that the more complicated "compassion" emerged later, when theory of mind, moral capacity, and eventually, our species' higher order thinking could be used in an integrated cognitive operation. We have more to say on compassion in the third paper in this series of three.

We consider the down-regulation of aggression as an important foundation for religious capacity in the second paper, drawing on Hare, Wobber, and Wrangham (2012). Reduced aggression in great apes (specifically, Pan paniscus, the bonobo, but not Pan troglodytes) is part of a trait complex of hormonal, morphological, physiological, behavioral, and psychological features that emerge along with a pattern of development that sees juvenile (paedomorphic) characteristics perpetuated into adulthood. In the evolutionary process, it is often the simplest explanation that prevails, so we propose the conservative change of a limited number of genes causing this multi- 
trait pattern in the ancestral ape population. These few mutations were broadly advantageous and affected many systems. That human process seems to fit the bonobo model ( $c f$ Hare, Wobber, and Wrangham 2012) - but only to an extent. The bonobo and human profiles of lowered aggression are very different indeed. We parse the cognitive differences in the second paper in this series of three.

In summary, we conclude that genetic drift in small populations could have endowed our line with some of its best and most problematical traits, by random mutation and then, by genetic drift and finally in some cases, natural selection. That is consistent with the many "slightly deleterious" genes that are part of our heritage. Lachance and Tishkoff write that, "Lower effective population sizes also influence the amount of slightly deleterious mutants that are segregating [involved in sex cell production]. If environmental conditions change, it is possible for the previously deleterious alleles to become adaptive” $(2013,136)$.

With these details on genetic drift, we begin to see that the evolution of the human genome may have relied on mechanisms that functioned in smaller populations, which were very likely subject to founder effects and repeated bottlenecks. One of these bottlenecks occurred 50-60,000 years ago, in the population of Homo sapiens that came out of Africa to found the rest of the human population on Earth. They had only a reduced, random draw from the genetic variability of the African population of Homo sapiens.

This was the last, large drop in genetic variability for non-African humans (except for the drop in variability among humans colonizing the Americas). Ancestors of the out-of-Africa population had survived others: from all Miocene great apes to African great apes, and from African great apes to the apes giving rise to chimpanzee and human lineages. Reduction in genetic variability may have placed a premium on mutations that were (or, were eventually) advantageous. Slightly deleterious genetic mutations built up, which would affect us all. Their prevalence and health consequences became bound up culturally with social roles and institutions that made use of human religious capacity. In hunting and gathering societies, healers and seers are most often one and the same.

\section{PLASTICITY, AN EVOLVED SOURCE OF HUMAN PHENOTYPIC VARIABILITY}

Plasticity means different things to the neurologist, the paleobiologist, the expert in genomics, and the cultural anthropologist. Yet, it appears that all meanings are somehow interconnected in the human species, and that they all find their origins in the organization of the brain and nervous system.

We address plasticity here because it implies, for all experts, a flexibility in the response of humans to their environment - a biologically-based ability to react and develop differentially according to varying circumstances, in addition to the patterns in their genome. Ultimately, plasticity implies adaptability imparted by the genome, and so, a type of variability - genetic at its foundation, but not the same genetic variability that we have been discussing as a population characteristic. Here, we interpret plasticity as a source of individual human phenotypic variability, but also as a possible trait or trait complex that varies by species. Our view is that plasticity evolved on the human lineage for specific reasons and with important consequences. 
Gómez-Robles and Sherwood (2016) cite Hublin, Neubauer and Gunz (2015) in observing that, "It is generally assumed that the shift towards a more altricial pattern of development observed during hominin evolution is associated with an increased level of neural plasticity due to slower brain growth over a longer period of time." This use of "altricial pattern" is equivalent to our definition of "secondary altriciality" for humans. It implies an extended developmental trajectory.

We shall discuss secondary altriciality further when we explore the bonobo model and how it informs our theories on the foundations of religious capacity, primarily in the second paper of this series of three. We have written elsewhere about the usefulness of "neuronal plasticity" in restoring synaptic homoeostasis through sleep (cf Tononi and Cirelli 2013; Rappaport and Corbally 2016; 2017). This finding strengthens theories on an important transition that must have been made by an early member of our genus - sleeping on the ground. Psychologist Coolidge and anthropologist Wynn propose that Homo erectus slept not in trees, in the ape pattern, but always on the ground, and that the species benefitted from long, deep, and REM sleep through improved learning, greater creativity, and the social rehearsal in dreams of actions taken during the day $(2009,129-130)$.

Features that are believed to be connected to plasticity vary between humans and chimpanzees, and between modern humans and extinct forms of humans, including Neanderthals and Denisovans. Comparisons of modern humans with these two earlier human species rely on the fact that most of the biology is the same, so we focus on the differences to determine which characteristics make modern humans different. The exact genomic and neural components of plasticity are just now beginning to emerge. It seems that plasticity, itself, may evolve, and may be different for different species. That unproven notion emerges quietly from the following comparative findings. Homo sapiens is gifted with a great deal of plasticity.

It is useful to remember that much happened on three evolutionary lines since our split with the chimpanzees - both the better known species, Pan troglodytes, and Pan paniscus, the bonobo.

Both species have evolved since their common ancestor split, so we should avoid interpreting the two modern species of Pan as duplicates of the ancestral ape common to us all. The fossil evidence suggests that the ancestral ape common to all three species resembled living chimpanzees more than humans (Young et al. 2015), in whom enormous changes in locomotion evolved. Our genus is the only one to make the full transition to upright posture and a bipedal gait. The australopithecines had a less efficient bipedal gait and their limb proportions were more apelike. It is only with the genus Homo that body and brain began to take on the proportions common to us all.

Emerging tentatively from the neurological and anthropological literatures has been the notion that brain anatomy and plasticity are somehow related to human culture. Gómez-Robles and Sherwood summarize the evidence for this idea, and much of it comes from research on humans and chimpanzees. They write that, "a number of comparative studies have been performed that report species differences in cortical anatomy that are thought to correlate with plasticity" (2016). Most important, human brains take longer to mature, so their developmental paths are attenuated, with vast consequences. 
To us, it makes good sense that our unique anatomical features would be connected to the trait that makes humans the most plastic of all in cognition and behavior, i.e., the biologically based trait of cultural capacity. We take this notion one step further. We suggest that if brain plasticity is related to culture, then it is surely important for the practice and theories (theologies) emerging from religious capacity. We see religious capacity as the "late comer" in the trio of culture (appearing first in the ancestral ape population common to humans and chimpanzees around 8-10 million years ago), moral capacity (in Homo erectus around 1 - 1.5 million years ago), and religious capacity (in Homo sapiens, fully at 150,000 years ago, with the stabilization of the globe-shaped skull). The timing of this sequence is important. Primates have been intensely "social" from early in the Cenozoic Era, 55-65 million years ago, but they became "cultural" only in the ancestral ape population common to chimpanzees and humans, as much as 48-50 million of years after primate sociality arose (Rappaport and Corbally 2017). Culture had a very different course on the two lines, coming to dominate human social life completely, but only weakly visible in modern chimpanzees.

Let us take a closer look at comparative research on human and chimpanzee developmental paths to see how plasticity, and so culture, emerged neurologically. Gómez-Robles and Sherwood (2016) write:

Plasticity is the propensity of the brain to be molded by external influences, including the ecological, social and cultural context. The impact of environmental influences in shaping human behavior has been long recognized but it has been only recently that scientists have started discovering the more pronounced plasticity of human brains compared to our close relatives.

Earlier, these authors published findings that showed the end-result of development is different for humans and chimpanzees. Gómez-Robles, Hopkins, Schapiro, and Sherwood (2015, 14799) report studies of human and chimpanzee MRI scans, which show that

...the morphology of the human cerebral cortex is substantially less genetically heritable than in chimpanzees and therefore is more responsive to molding by environmental influences. This anatomical property of increased plasticity, which is likely related to the human pattern of development, may underlie our species’ capacity for cultural evolution.

In other words, the human brain changes during development because it is more "plastic," and how and where it is more plastic is important. The authors cite findings by Hill et al. (2010) that, "Low heritability values are observed in association areas, which also show the greatest expansion from birth to adulthood and during primate evolution" (Gómez-Robles and Sherwood 2016). They point to findings by Fjell and colleagues (2015) that changes in association areas correlate with results on cognitive tests that reflect intellectual ability. Association areas take longer to develop, which is consistent with a need for longer and later development of them. Those association areas are critical in human planning, problem-solving, and creativity in science, art, and religion. 
Neuroscientist Michael Gazzaniga and colleagues write that, "different regions of the human brain develop at different rates, with association areas lagging behind sensory and motor structures...” (Gazzaniga et al. 2009, 101). In summary, low heritability for cortical organization and a period of lengthening maturation for association areas, along with related measures of human intellect, together suggest that plasticity is greater for the parts of the human brain that are especially important for higher order thinking. They evolved late.

We have noted previously that the expansion of anthropoid brain size began before the last common ancestor to humans, chimpanzees, and gorillas. Great apes have relatively large brains, for mammals. Still, the traits that catch our attention are not simply size, but the unique neurological features of humans. Sakai and colleagues (2012) point out that increases in brain volume show an extended trajectory in both chimpanzees and humans, but a much greater increase in white matter volume during the early infancy of humans. Gómez-Robles and Sherwood (2016) speculate that the growth in human brain tissues, which is driven by an elaboration of neural connections, could well have emerged after the evolutionary split between chimpanzees and humans.

Teasing apart similarities and differences can help to identify unique human traits, in particular, the neurological basis upon which human plasticity operates. Gómez-Robles and Sherwood (2016) describe evidence that prefrontal neuronal distribution and dendritic morphology are similar in humans and chimpanzees, but in humans, myelination is extended developmentally beyond late adolescence. We note that this has enormous consequences for the social and cultural life of humans, who often begin to assume some adult responsibilities long before their brains are fully mature. Societies have engineered a variety of compensatory mechanisms to support this lengthened immaturity - not least of which are religious, educational, and familial structures to support young adults.

Gómez-Robles and Sherwood (2016) point to work by Miller and colleagues (2012) in proposing that the extended neurological development of humans may be an "adaptation to further refine executive and cognitive functions that characterize the transition from adolescence to early adulthood in humans." There is still another function of the extended period of neurological development in humans: "pruning of synaptic spines in the prefrontal cortex" (Petanjek et al., 2011). Later brain maturation is expected to have "a less critical role in increasing brain plasticity than the initial postnatal period... However, the adolescent period has been suggested to be important in the acquisition of social skills and in the establishment of adult forms of language and communication...” (Gómez-Robles and Sherwood 2016).

We understand that the late adolescent period is especially important in the emergence and refinement of cultural, moral, and religious capacities, and practice in their use. We have previously written that maturation is delayed for human children to good purpose. Earlier maturation would prevent the easy, unself-conscious acquisition of social and cultural conventions (Rappaport and Corbally 2016, 861). While children participate socially in some religious activities in a manner that does not signal assumption of adult understanding, it is very difficult for children to acquire adult moral competence. This usually does not occur until well into adulthood, and sometimes it does not happen at all. The few exceptions capture our attention. 
We propose that religious capacity is fulfilled even later developmentally than moral capacity, and, that it evolved later. In the second and third papers in this series of three, in our discussion of brain expansion and the emergence of theologies, we emphasize that it is the functioning of the parietal lobes in conjunction with prefrontal areas that signals an ability to imagine spaces and beings, achieve a deep sense of "selflessness," and construct theologies about the relationships between humans and the supernatural that are consistent with the overall culture. In late adolescence, the assumption of theologies (and theology-like belief systems, sometimes aberrant ones) requires - and acquires - some of the dispassionate reasoning that we have described previously for moral capacity (Rappaport and Corbally 2016; 2017).

We see religious capacity as quite different from moral capacity, emerging only when certain parts of the human brain expanded in Homo sapiens. Our view is that Bruner and colleagues (Bruner and Iriki 2016, Fig. 5; Bruner et al. 2017) make a good case that Homo sapiens is the only fossil that has the globular skull to accommodate this expansion. While brain development in children lays a good foundation for the higher order thinking we find in the science, art, and religion of Homo sapiens, it is only in late adolescence and early adulthood that religious capacity and moral capacity co-mingle to fully support the social group - even if, the culture of that social group includes some rules and rituals that are, to us, reprehensible and inhumane. Religion co-opts many of the adult "social skills and adult forms of... communication" (as noted by Gómez-Robles and Sherwood 2016), which we see used, in an earlier species (Homo erectus), to serve morality's goals of (1) clearly stating rules publicly, (2) reducing adult dysfunctional emotional states, (3) making decisions on moral infractions, and (4) giving the group hope for the future (Rappaport and Corbally 2016;2017).

Human brain development must remain plastic until these early-adult competencies are mastered and supported, in part, by cultural expressions of religious capacity. And, it does. It is important to note that other social institutions, such as voluntary associations (e.g., Rotary clubs, insurance co-ops, scout troops, fraternities, and military organizations) also co-opt some of morality's purpose, to support the social group in ways that are often inter-mingled with religious teachings. Eugene Harris notes the following implications of the human developmental profile.

We have discovered several genes that appear to contribute to our unique brains by influencing neuron shape or by helping the proliferation and differentiation of brain cells during development. We have also detected many genes that appear to have undergone adaptation to increase the energy supply to our brain, and we have found at least one gene that contributes to human language, though others most certainly will be found. Moreover, the success of gene expression studies has shown us that certain sets of genes are very differently expressed in human brains compared to chimpanzee brains, and that some molecular differences between chimpanzee and human brains seem to be related to the prolongation of development of the human brain, perhaps allowing our children to develop their brains over a longer period of time in rich experiential contexts (2015, 109-110). 


\section{TOWARD A MODEL FOR THE SEQUENTIAL EMERGENCE OF RELIGIOUS CAPACITY IN THE GENUS HOMO}

In this, the first of three papers building a theoretical model for the emergence of religious capacity in the genus Homo, we have identified and placed essential building blocks of its evolutionary foundation: primate sociality, which developed 55-65 million years ago; a basic ape model from the Miocene, at about 19 million years ago (with Proconsul); a down-regulation of aggression and uptick in social tolerance, appearing in at least some groups of the ape population that gave rise to the bonobos, chimpanzees, and humans, beginning around 8-10 million years ago; the emergence of moral capacity in Homo erectus, around 1-1.5 million years ago; and the integration of moral and religious capacities when Homo sapiens fully evolved with expanded parietals and a globular skull, just 150,000 years ago. In evolutionary terms, human religious capacity is not very old. In the second paper, we shall identify specific changes, explore their possible genomic origins, and sketch the full flowering of religious capacity with the expansion of the parietal lobes in our species, Homo sapiens.

It is important to note when cultural capacity emerged. Our view is that the rudiments of cultural capacity were in the same ancestral ape population giving rise to the bonobos, chimpanzees, and humans, because all of these species evidence culture - humans, strongly, and the others, weakly. We speculate on the timing of these three capacities in noting this sequence: cultural capacity - rudiments in the ape population around 8-10 million years ago; moral capacity in Homo erectus at 1-1.5 million years ago; and religious capacity with the stabilization of the globe-shaped skull in Homo sapiens at 150,000 years ago.

One of the themes of this first paper has been our origination in a strong, genetically variable population of Miocene apes, and how the human lineage has managed to become one of the most adaptive and plastic of species with a reduced genetic complement from it. We have discussed the possible role of genetic drift in creating variability in small populations of hominins. That theme continues in the second paper by asking what types of traits might have emerged due to genetic drift.

Finally, in this paper we began our exploration of human plasticity, its relation to cultural capacity, and its growth with the lengthening of lifespan throughout anthropoid evolution, until our biology finally comes to reflect and respond developmentally to the culture we are born to. In the second paper, we pick up this notion and explore it in our closest relatives - other members of the genus Homo.

Let us hasten to add that there are other mechanisms - in addition to genetic drift and (phenotypic) plasticity - that operate in both small and large populations, just like natural selection and genetic drift both operate to create variability. These other mechanisms can potentially affect genetic and phenotypic variability of the human lineage. They include: cryptic genetic variation (CGV) (Wray 2013; Paaby and Rockman 2014); genetic draft (not drift) (Neher 2013); epigenetics, often covered as an aspect of human plasticity (Duncan, Gluckman, and Dearden 2014); "hidden adaptations” (Harris 2015, 86-7); and canalization/ decanalization/ recanalization (Gibson 2009; Sgrò, Wegener, and Hoffmann 2010). Knowledge of these mechanisms is relatively new, but growing fast. Later treatments of the biological evolution of 
religious capacity on the human line, by others in the future, will no doubt include some of these, as more is known about them and our very own human genome.

\section{REFERENCES}

Aiello, Leslie C., and Robin I. M. Dunbar. 1993. "Neocortex Size, Group Size, and the Evolution of Language.” Current Anthropology 34: 184-93.

Arnold, Michael L. 2008. Reticulate Evolution and Humans: Origins and Ecology. Oxford: Oxford University Press.

Bakewell, Margaret A., Peng Shi, and Jianzhi Zhang. 2007. "More Genes Underwent Positive Selection in Chimpanzee Evolution than in Human Evolution.” Proceedings of the National Academy of Sciences 104(18): 7489-7494.

Begun, David R. 2003. “Planet of the Apes.” Scientific American 289(2): 74-83. Fossil ape reconstructions by John Gurche. . 2016. The Real Planet of the Apes; A New Story of Human Origins. Princeton:

Princeton University Press.

Bruner, Emiliano, and Osbjorn Pearson. 2013. "Neurocranial Evolution in Modern Humans: The Case of Jebel Irhoud 1.” Anthropological Sciences 121: 31-41.

Bruner, Emiliano, and Atsushi Iriki. 2016. "Extending Mind, Visuospatial Integration, and the Evolution of the Parietal Lobes in the Human Genus.” Quaternary International 405: 98-110.

Bruner, Emiliano, Todd M. Preuss, Xu Chen, and James K. Rilling. 2017. "Evidence for Expansion of the Precuneus in Human Evolution.” Brain Structure and Function 222:1053-1060.

Casanovas-Vilar, Isaac, David M. Alba, Miguel Garcés, Josep M. Robles, and Salvador MoyàSolà 2011. "Updated Chronology for the Miocene Hominoid Radiation in Western Eurasia." Proceedings of the National Academy of Sciences 108 (14): 5554-5559.

Caspermeyer, Joseph. 2016. “Scientists Explore a Master Genetic Switch That Plays a Key Role in Energy Metabolism and Human Brain Evolution and Function.” Molecular Biology and Evolution. Online, April 21.

Cochran, Gregory, and Henry Harpending. 2010. The 10,000 Year Explosion: How Civilization Accelerated Human Evolution. New York: Basic Books.

Colagè, Ivan. 2015. “The Human Being Shaping and Transcending Itself: Written Language, Brain, and Culture.” Zygon: Journal of Religion and Science 50:1002-21. 
Coolidge, Frederick L., and Thomas Wynn. 2009. The Rise of Homo sapiens; The Evolution of Modern Thinking. Chichester, UK: Wiley-Blackwell.

Corbally, Christopher J., and Margaret Boone Rappaport. 2013. “Crossing the Latest Line: The Evolution of Religious Thought as a Component of Human Sentience.” In Evolution:

Development within Big History, Evolutionary and World-System Paradigms, Yearbook, ed. Leonid E. Grinin and Andrey. V. Korotayev, 197-218. Volgograd, Russia: Uchitel Publishing.

Duncan, Elizabeth J., Peter D. Gluckman, and Peter K. Dearden. 2014. “Epigenetics, Plasticity, and Evolution: How Do We Link Epigenetic Change to Phenotype?” Journal of Experimental Zoology Part B: Molecular and Developmental Evolution 322B: 208-220.

Fjell , Anders M., Lars T. Westlye, Inge Amlien, Christian K. Tamnes, Håkon Grydeland, Andreas Engvig, Thomas Espeseth, Ivar Reinvang, Astri J. Lundervold, Arvid Lundervold, and Kristine B. Walhovd. 2015. "High-expanding Cortical Regions in Human Development and Evolution Are Related to Higher Intellectual Abilities.” Cerebral Cortex 25(1):26-34.

Fleagle, John G., Zelalem Assefa, Francis H. Brown, and John J. Shea. 2008.

"Paleoanthropology of the Kibish Formation, Southern Ethiopia: Introduction." Journal of Human Evolution 55(3): 360-365.

Garner, David. 2015. "Vulnerability Made Us Human: How Our Early Ancestors Turned Disability into Advantage.” Phys.org. Online, June 15.

Gazzaniga, Michael S. 1999. “The Interpreter Within: The Glue of Conscious Experience.” Dana Foundation web site, April 1.

http://www.dana.org/Cerebrum/Default.aspx?id=39343\#sthash.I7zCiFeL.dpuf

Gazzaniga, Michael S., Richard B. Ivry, George R. Mangun, with Megan S. Steven. 2009. Cognitive Neuroscience. Third Edition. New York, NY: W.W. Norton.

Gibson, Greg. 2009. “Decanalization and the Origin of Complex Disease.” Nature Reviews Genetics 10, 134-140.

Gómez-Robles, Aida, and Chet C. Sherwood. 2016. "Human Brain Evolution; How the Increase of Brain Plasticity Made Us a Cultural Species.” MÈTODE Science Studies Journal (May). Online [no page numbers], Universitat de València. DOI: 10.7203/metode.7.7602

Gómez-Robles, Aida, William D. Hopkins, Steven J. Schapiro, and Chet C. Sherwood. 2015. "Relaxed Genetic Control of Cortical Organization in Human Brain Compared with Chimpanzees.” Proceedings of the National Academy of Sciences 112(48): 14799-14804.

Hare, Brian, Victoria Wobber, and Richard Wrangham. 2012. "The Self-Domestication Hypothesis: Evolution of Bonobo Psychology Is Due to Selection Against Aggression.” Animal Behaviour 83(3): 573-585. 
Harpending, Henry C., Mark A. Batzer, Michael Gurven, Lynn B. Jorde, Alan R. Rogers, and Stephen T. Sherry. 1998. "Genetic Traces of Ancient Demography.” Proceedings of the National Academy of Sciences 95: 1961-1967.

Harris, Eugene E. 2015. Ancestors in Our Genome; the New Science of Human Evolution. Oxford: Oxford University Press.

Harris, Eugene E. and Jody Hey. 1999. "X Chromosome Evidence for Ancient Human Histories.” Proceedings of the National Academy of Sciences 96(6): 3320-3324.

Hawks, John. 2008. “The ‘Dark Matter’ of Modern Human Origins.” John Hawks weblog. Online, March 1.

Hublin, Jean-Jacques, Abdelouahed Ben-Ncer, Shara E. Bailey, Sarah E. Freidline, Simon Neubauer, Matthew M. Skinner, Inga Bergmann, Adeline Le Cabec, Stefano Benazzi, Katerina Harvati and Philipp Gunz. 2017. "New fossils from Jebel Irhoud, Morocco and the pan-African origin of Homo sapiens.” Nature 546: 289-292.

Hublin, Jean-Jacques, Simon Neubauer, and Philipp Gunz. 2015. "Brain Ontogeny and Life History in Pleistocene Hominins.” Philosophical Transactions of the Royal Society B, 370 (1663), 20140062.

Korsgaard, Christine. 2009. "Morality and the Distinctiveness of Human Action.” In Primates and Philosophers: How Morality Evolved, edited by Frans De Waal, 98-119. Princeton, NJ: Princeton University Press.

Kuzawa, Christopher W., Harry T. Chugani, Lawrence I. Grossman, Leonard Lipovich, Otto Muzik, Patrick R. Hof, Derek E. Wildman, Chet C. Sherwood, William R. Leonard, and Nicholas Lange. 2014. "Metabolic Costs and Evolutionary Implications of Human Brain Development.” Proceedings of the National Academy of Sciences 111(36): 13010-130-15.

Lachance, Joseph, and Sarah A. Tishkoff. 2013. "Population Genomics of Human Adaptation.” Annual Review of Ecology, Evolution, and Systematics 44:123-143.

Langergraber, Kevin E., Kay Prufer, Carolyn Rowney, Christophe Boesch, Catherine Crockford, Katie Fawcett, Eiji Inoue, Miho Inoue-Muruyama, John C. Mitani, Martin N. Muller, Martha M. Robbins, Grit Schubert, Tara S. Stoinski, Bence Viola, David Watts, Roman M. Wittig, Richard W. Wrangham, Klaus Zuberbühler, Svante Pääbo, and Linda Vigilant. 2012. "Generation Times in Wild Chimpanzees and Gorillas Suggest Earlier Divergence Times in Great Ape and Human Evolution.” Proceedings of the National Academy of Sciences 109(39): 15716-15721.

Lévi-Strauss, Claude. 1973 [1955]. Tristes Tropiques. English translation by John and Doreen Weightman. New York: Atheneum.

Lieberman, Daniel E. 2008. "Speculations about the Selective Basis for Modern Human Craniofacial Form.” Evolutionary Anthropology 17: 55-68. 
Pantheon Press.

2013. The Story of the Human Body: Evolution, Health and Disease. New York:

MacLean, Evan L. 2016. "Unraveling the Evolution of Uniquely Human Cognition.”

Proceedings of the National Academy of Sciences 113(23): 6348-6354.

Matute, Daniel R. 2013. "The Role of Founder Effects on the Evolution of Reproductive Isolation.” Journal of Evolutionary Biology 26: 2299-2311.

Miller, D. J., T. Duka, C. D. Stimpson, S. J. Schapiro, W. B. Baze, M. J. McArthur, ..., C. Chet Sherwood. 2012. "Prolonged Myelination in Human Neocortical Evolution." Proceedings of the National Academy of Sciences 109(41): 16480-16485. [get rest of authors]

Neher, Richard A. 2013. "Genetic Draft, Selective Interference, and Population Genetics of Rapid Adaptations.” Annual Review of Ecology, Evolution, and Systematics 44:195-215.

O’Bleness, Majesta, Veronica B. Searles, Ajit Varki, Pascal Gagneux, and James M. Sikela. 2012. "Evolution of Genetic and Genomic Features Unique to the Human Lineage." Nature Reviews Genetics 13: 853-66.

Paaby, Annalise B., and Matthew V. Rockman. 2014. “Cryptic Genetic Variation, Evolution’s Hidden Substrate.” Nature Reviews Genetics 15(4): 247-258.

Pagel, Mark. 2012. Wired for Culture; Origins of the Human Social Mind. New York: W. W. Norton \& Company.

Petanjek, Zdravko, Miloš Judaš, Goran Šimić, Mladen Roko Rašin, Harry B. M. Uylings, Pasko Rakic, and Ivica Kostović. 2011. "Extraordinary Neoteny of Synaptic Spines in the Human Prefrontal Cortex.” Proceedings of the National Academy of Sciences 108(32): 13281-13286.

Pollard, Katherine S. 2013. “What Makes Us Different?” Scientific American 22 (Special Collector's Edition 1):30-35.

Prado-Martínez, Javier, Peter H. Sudmant, Jeffrey M. Kidd, Heng Li, Joanna L. Kelley, Belen Lorente-Galdos, Krishna R. Veeramah, August E. Woerner, Timothy D. O’Connor, Gabriel Santpere, Alexander Cagan, Christoph Theunert, Ferran Casals, Hafid Laayouni, Kasper Munch, Asger Hobolth, Anders E. Halager, Maika Malig, Jessica Hernandez-Rodriguez, Irene HernandoHerraez, Kay Prüfer, Marc Pybus, Laurel Johnstone, Michael Lachmann, and Can Alkan, Dorina Twigg, Natalia Petit, Carl Baker,Fereydoun Hormozdiari, Marcos Fernandez-Callejo, Marc Dabad, Michael L. Wilson, Laurie Stevison, Cristina Camprubí, Tiago Carvalho, Aurora RuizHerrera,Laura Vives, Marta Mele, Teresa Abello, Ivanela Kondova, Ronald E. Bontrop, Anne Pusey, Felix Lankester, John A. Kiyang, Richard A. Bergl,Elizabeth Lonsdorf, Simon Myers, Mario Ventura, Pascal Gagneux, David Comas, Hans Siegismund, Julie Blanc, Lidia Agueda-Calpena, Marta Gut, Lucinda Fulton, Sarah A. Tishkoff, James C. Mullikin, Richard K. Wilson, Ivo G. Gut, Mary Katherine Gonder, Oliver A. Ryder, Beatrice H. Hahn, Arcadi Navarro, Joshua M. Akey, Jaume Bertranpetit, David Reich, Thomas Mailund, Mikkel H. 
Schierup, Christina Hvilsom, Aida M. Andrés, Jeffrey D. Wall, Carlos D. Bustamante, Michael F. Hammer, Evan E. Eichler, and Tomas Marques-Bonet. 2013. “Great Ape Genetic Diversity and Population History.” Nature 499: 471-475.

Rappaport, Margaret Boone, and Christopher Corbally. 2015. Matrix Thinking: An Adaptation at the Foundation of Human Science, Religion, and Art. Zygon; Journal of Religion and Science 50(1): 84-112.

. 2016. “The Human Hearth and the Dawn of Morality.” Zygon: Journal of Religion and Science 51(4): 835-866. . 2017. "Human Phenotypic Morality and the Biological Basis for Knowing Good." Zygon: Journal of Religion and Science 52(3): 822-846.

. 2018a. "Evolution of Religious Capacity in the Genus Homo: Origins and Building Blocks.” Zygon: Journal of Religion and Science. . 2018b. "Evolution of Religious Capacity in the Genus Homo: Cognitive Time Sequence.” Zygon: Journal of Religion and Science. . 2018c. "Evolution of Religious Capacity in the Genus Homo: Trait Complexity in Action through Compassion” Zygon: Journal of Religion and Science.

Sakai, T. M. Matsui, A. Mikami, L. Malkova, Y. Hamada, M. Tomonaga, ... T. Matsuzawa. 2012. "Developmental Patterns of Chimpanzee Cerebral Tissues Provide Important Clues for Understanding the Remarkable Enlargement of the Human Brain.” Proceedings of the Royal Society B 280 (1753), 20122398.

Scally, Aylwyn, Julien Y. Dutheil, LaDeana W. Hillier, Gregory E. Jordan, Ian Goodhead, Javier Herrero, Asger Hobolth, Tuuli Lappalainen, Thomas Mailund, Tomas Marques-Bonet, Shane McCarthy, Stephen H. Montgomery, Petra C. Schwalie, Y. Amy Tang, Michelle C. Ward, Yali Xue, Bryndis Yngvadottir, Can Alkan, Lars N. Andersen, Qasim Ayub, Edward V. Ball, Kathryn Beal, Brenda J. Bradley, Yuan Chen, Chris M. Clee, Stephen Fitzgerald, Tina A. Graves, Yong Gu, Paul Heath, Andreas Heger, Emre Karakoc, Anja Kolb-Kokocinski, Gavin K. Laird, Gerton Lunter, Stephen Meader, Matthew Mort, James C. Mullikin, Kasper Munch, Timothy D.

O’Connor, Andrew D. Phillips, Javier Prado-Martinez, Anthony S. Rogers, Saba Sajjadian, Dominic Schmidt, Katy Shaw, Jared T. Simpson, Peter D. Stenson, Daniel J. Turner, Linda Vigilant, Albert J. Vilella, Weldon Whitener, Baoli Zhu, David N. Cooper, Pieter de Jong, Emmanouil T. Dermitzakis, Evan E. Eichler, Paul Flicek, Nick Goldman, Nicholas I. Mundy, Zemin Ning, Duncan T. Odom, Chris P. Ponting, Michael A. Quail, Oliver A. Ryder, Stephen M. Searle, Wesley C. Warren, Richard K. Wilson, Mikkel H. Schierup, Jane Rogers, Chris TylerSmith, and Richard Durbin. 2012. "Insights into Hominid Evolution from the Gorilla Genome Sequence.” Nature 483: 169-175.

Schrago, Carlos G. 2014. "Estimation of the Ancestral Effective Population Sizes of African Great Apes under Different Selection Regimes.” Genetica 142: 273-280. . 2013. "The Effective Population Sizes of the Anthropoid Ancestors of the HumanChimpanzee Lineage Provide Insights on the Historical Biogeography of the Great Apes.” Molecular Biology and Evolution 31(1): 37-47. 
Sgrò, Carla M., Benjamin Wegener, and Ary A. Hoffmann. 2010. “A Naturally Occurring Variant of Hsp90 That Is Associated with Decanalization.” Proceedings of the Royal Society B 277(2049-2057.

Thompson-Schill, Sharon L., Michael Ramscar, and Evangelia G. Chrysikou. 2009. "Cognition Without Control: When a Little Frontal Lobe Goes a Long Way.” Current Directions in Psychological Science 18(5): 259-63.

Tononi, Giulio, and Chiara Cirelli. 2014. "Sleep and the Price of Plasticity: From Synaptic and Cellular Homeostasis to Memory Consolidation and Integration.” Neuron 81(1):12-34.

Van Slyke, James A. 2011. The Cognitive Science of Religion. Burlington, VT: Ashgate Publishing.

Varki, Ajit, and Tasha K. Altheide. 2005. "Comparing the Human and Chimpanzee Genomes: Searching for Needles in a Haystack.” Genome Research 15: 1746-1758.

Weaver, Timothy D. and Roseman, Charles C. 2008. "New Developments in the Genetic Evidence for Modern Human Origins.” Evolutionary Anthropology 17: 69-80.

doi:10.1002/evan.20161

Whiten, Andrew. 1999. “The Evolution of Deep Social Mind in Humans.” In The Descent of Mind: Psychological Perspectives on Hominid Evolution, edited by Michael Corballis and Stephen E. G. Lea, 173-93. Oxford, England: Oxford University Press.

Whiten, Andrew, and David Erdal. 2012. "The Human Socio-Cognitive Niche and Its Evolutionary Origins.” Philosophical Transactions of the Royal Society B 367:2119-29.

Winder, Nick P., and Winder Isabelle C. 2015. "Complexity, Compassion and Self-Organisation: Human Evolution and the Vulnerable Ape Hypothesis.” Internet Archaeology 40.

dx.doi.org/10.11141/ia.40.3

Wray, Gregory A. 2013. “Genomics and the Evolution of Phenotypic Traits.” Annual Review of Ecology, Evolution, and Systematics 44: 51-72.

Young, Nathan M., Terence D. Capellini, Neil T. Roach, and Zeresenay Alemseged. 2015.

"Fossil Hominin Shoulders Support an African Ape-like Last Common Ancestor of Humans and Chimpanzees.” Proceedings of the National Academy of Sciences 112(38): 11829-11834. 